\title{
Urban air quality, climate, and pollution: from measurement to modeling applications
}

\author{
Taciana Toledo de Almeida Albuquerque ${ }^{1}$ - Jane Meri Santos ${ }^{2} \cdot$ Maria de Fatima Andrade $^{3}$
}

Published online: 23 May 2020

(C) Springer-Verlag GmbH Germany, part of Springer Nature 2020

This special issue on air pollution and modeling applications is dedicated to publishing selected abstracts presented at the 4th Community Modeling and Analysis System (CMAS) South America (https://cmasconference.com.br). The 4th CMAS South America event was held in Belo Horizonte, Minas Gerais State, Brazil, from 22 to 24, 2019. Previous CMAS events in South America were in Sao Paulo (Brazil 2013), Bogota (Colombia - 2015), and Vitória (Brazil - 2017) , with a significant number of participants each year. In Belo Horizonte, we had a total number of 180 posters, 90 oral presentations, five Keynote Speakers, and six special sessions. Previous to the conference, we had 5-day courses on air quality numerical modeling and industrial ventilation. After the conference, we had a 1-day course about aerosol measurements and source apportionment for air quality management. Also, a technical tour was offered to evaluate the impacts on the physical environment resulting from the collapse of the Fundão Dam, Mariana, Minas Gerais.

The conference sections included: Air Quality, Climate and Energy; Emissions Inventories, Models, and Processes; Model Development; Model Development; Modeling to Support Exposure and Health Studies and Community-scale Applications; Regulatory Modeling and SIP Applications; Remote Sensing/Measurements Studies/New Sensors Technologies; Atmospheric Boundary Layer: Observing and

Responsible editor: Philippe Garrigues

Taciana Toledo de Almeida Albuquerque taciana@desa.ufmg.br

1 Department of Sanitary and Environmental Engineering, Universidade Federal de Minas Gerais, Belo Horizonte, Brazil

2 Department of Environmental Engineering, Universidade Federal do Espírito Santo, Vitória, Brazil

3 Department of Atmospheric Sciences, Institute of Astronomy, Geophysics and Atmospheric Sciences, Universidade de São Paulo, São Paulo, Brazil
Modeling; Environmental Odors; Management of Gaseous Emissions in Sewage Treatment Plants; Air Pollution Control; and Air Pollution at Critical Infrastructure Sites and Its Influence for the Society. The abstracts presented in the Conference are available on-line in the proceedings (https:// cmasconference.com.br/wp-content/uploads/2019/10/LivroAir-Pollution-2019-Final-V03-min.pdf).

It was considered very valuable also for the tightening of groups from South America with other countries and institutions, in particular, the CMAS in the USA. The previous conference of CMAS South America focused mainly in the field of air quality modeling. Still, the recognition of its importance in South America turned it to an Air Pollution meeting, bringing together most of the involved researchers and students. Moreover, it was an opportunity to improve the knowledge and skills involved in the air quality modeling field. At that time, there was not enough expertise in the subject of Chemical Atmospheric Modeling. It was a very inspiring experience that brought to the field students from different groups from Brazil and South America.

In this special issue, we can have an idea of the maturity and innovation research that is underway in South America. Authors from Brazil, Bolivia, Colombia, and Chile present their results from regional to high-resolution modeling, including new experimental setups and databases. Presented in this special issue is the discussions related to air pollution effects due to changing the transport system and monitoring of $\mathrm{PM}_{10}$ and $\mathrm{PM}_{2.5}$ in Bogotá, Colombia, and the modeling of air quality in the Andes, bringing new information related to areas with few published data available.

The state-of-art developments of emission inventories were also presented to South America, and to Brazil in particular, including the industrial emission of particles and even the emissions of burning wood in pizzerias that have an impact on air quality in Latin America cities. The health impact of pollutants was also addressed in the study of mortality rate due to sulfur dioxide and the prevention of hospital admissions due to the implementation of new air quality standard 
regulations. Biomonitoring considering the role of magnetic properties of the particles is presented, illustrating the possibilities of this new approach. Finally, the importance of studying atmospheric aerosols is worth emphasizing due to many important aspects that have not been resolved mainly in the South Hemisphere, where we have a lack of experimental data and human resources in the experimental and modeling areas.

The world is facing new challenges related to diseases disseminated by a virus, and this example of the COVID-19 showed that the population that was more exposed to air pollution during the lifetime was more susceptible to face worst respiratory outcomes. Another analysis related to the transportation of the virus as an aerosol is a significant interrogation to be addressed. We must invest in science, forming the new generations of researches to be prepared to complicate and multi-discipline problems, among them the issues related to air quality and its impacts.

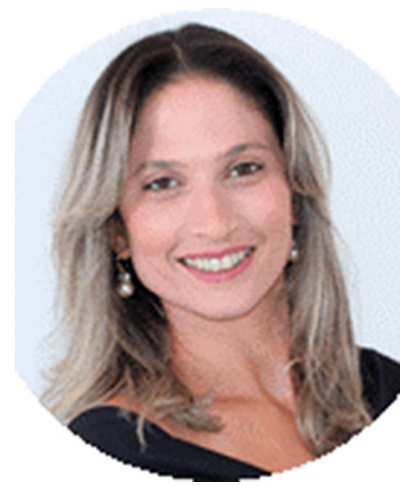

Taciana Toledo de Almeida Albuquerque is a graduate of Meteorology from the Federal University of Alagoas and got her master's and Ph.D. in Atmospheric Sciences at the Institute of Astronomy, Geophysics and Atmospheric Sciences of the University of São Paulo. She is an adjunct Professor at the Federal University of Minas Gerais of the Department of Sanitary and Environmental Engineering. She has experience in Atmospheric Sciences with a focus on air pollution on the following topics: air pollution control, atmospheric monitoring, atmospheric dispersion, quantification and characterization of atmospheric particles in urban environments, control plans of atmospheric emissions, chemical transport models, and meteorological models.

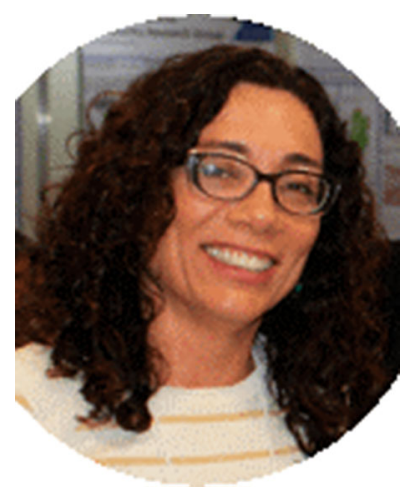

Jane Meri Santos is a graduate of Mechanical Engineering from the Federal University of Espírito Santo (UFES), and got a master's degree in Mechanical Engineering from the Pontifical Catholic University of Rio de Janeiro and a Ph.D. in Chemical Engineering from the University of Manchester. She is a Full Professor in the Department of Environmental Engineering at the UFES, and she has experience in computational transport and atmospheric turbulence phenomena, with applications in the emission and atmospheric dispersion of particles, odorous gases, and volatile organic compounds in urban and industrial environments.

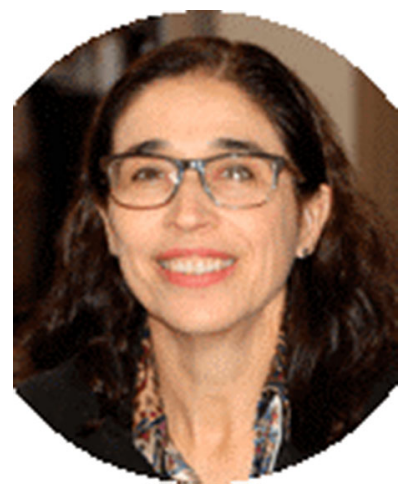

receiver models.
Maria de Fatima Andrade is a graduate of Physics from the University of São Paulo (USP) and got her master's and Ph.D. in Physics from USP. She is a full professor at the Institute of Astronomy, Geophysics and Atmospheric Sciences at USP. She has experience in the field of Geosciences, with an emphasis on Atmospheric Pollution, acting mainly on the following topics: atmospheric chemistry, photochemical models, atmospheric aerosols, air quality models, and 